\title{
ISOLASI SENYAWA ALKALOID TURUNAN FUROKUINOLIN DARI RANTING Toddalia asiatica L. DAN UJI AKTIVITAS ANTIKANKER
}

\author{
Devina Oktari Rahayu, Tjitjik Srie Tjahjandarie, Mulyadi Tanjung*1 \\ ${ }^{1}$ Kimia Organik Bahan Alam, Departemen Kimia, Fakultas Sains dan Teknologi, Universitas Airlangga, \\ Surabaya \\ *email: mulyadi-t@fst.unair.ac.id
}

Received 20 October 2018

Accepted 20 December 2018

\begin{abstract}
Abstrak
Toddalia asiatica merupakan tumbuhan perdu yang tersebar di Afrika, Asia, Madagascar, dan Australia (Hu et al., 2015). Senyawa metabolit sekunder yang ditemukan tumbuhan Toddalia asiatica L. adalah alkaloid. Ekstraksi senyawa alkaloid dari tumbuhan Toddalia asiatica L. dengan cara maserasi menggunakan pelarut metanol pada suhu kamar. Proses isolasi dilakukan melalui fraksinasi dan pemurnian menggunakan kromatografi kolom gravitasi, dan kromatografi radial. Hasil isolasi yang didapatkan merupakan senyawa alkaloid turunan furokuinolin yaitu skimmianin. Struktur senyawa alkaloid turunan furokuinolin yang diketahui melalui analisa hasil spektroskopi UV, IR, 1D NMR $\left({ }^{1} \mathrm{H}-\mathrm{NMR}\right.$ dan $\left.{ }^{13} \mathrm{C}-\mathrm{NMR}\right)$, serta 2D NMR (HMBC dan HMQC) dan uji aktivitas antikanker terhadap sel kanker murin leukemia P-388.
\end{abstract}

Kata kunci : Alkaloid turunan furokuinolin, skimmianin, Toddalia asiatica L., antikanker

\begin{abstract}
Toddalia asiatica L. is a bushy plant that spreads in Africa, Asia, Madagascar, and Australia (Hu et al., 2015). The secondary metabolite compound found in Toddalia asiatica L. is alkaloid. Extraction of alkaloid compounds from Toddalia asiatica L. by maceration using methanol at room temperature. The isolation process is diluted by fractionation and purification using column chromatography of gravity and radial chromatography. The result of isolation is an alkaloid compound derived furokuinolin, skimmianin. The structure of alkaloid compounds derived from furokuinolin known through spectroscopic analysis including UV, IR, 1D NMR ( ${ }^{1} \mathrm{H}-\mathrm{NMR}$ and ${ }^{13} \mathrm{C}-\mathrm{NMR}$ ), and 2D NMR (HMBC and HMQC) and the anticancer activity test against the cancer cells murine P-388.
\end{abstract}

Key word : Alkaloid compound derived furokuinolin, skimmianin, Toddalia asiatica L., anticancer

\section{Pendahuluan}

Toddalia merupakan salah satu genus dari famili Rutaceae dengan penyebaran di Afrika, Asia, Madagaskar, dan Australia (Hu et al., 2015). Toddalia asiatica atau dikenal dengan nama lokal 'akar kucing' merupakan jenis tumbuhan perdu. Senyawa metabolit sekunder yang terdapat dalam Toddalia asiatica antara lain senyawa golongan alkaloid, kumarin, dan terpenoid yang memperlihatkan bioaktivitas sebagai antiinflamasi, antimikroba, antimalarial, anti HIV, anti feedant, dan antikanker (Li et al., 2017, Qui et al., 2012). Senyawa 
alkaloid Toddalia asiatica memperlihatkan aktivitas antikanker terhadap sel kanker payudara, sel kanker usus besar, dan kanker kulit (Hirunwong et al., 2016).

Penelitian ini bertujuan untuk mengisolasi dan menentukan struktur senyawa golongan alkaloid yang terkandung dalam ranting Toddalia asiatica. Dan senyawa alkaloid hasil isolasi diuji aktivitas antikanker terhadap sel murine leukemia P-388.

\section{Metode Penelitian}

Prosedur Umum

Pemisahan dan pemurnian dengan kromatografi kolom gravitasi (KKG) menggunakan silika gel $\mathrm{G}_{60}$, kromatografi radial menggunakan silika gel $60 \mathrm{PF}_{254}$ (Merck), dan kromatografi lapis tipis (KLT) menggunakan plat KLT Kieselgel $60 \quad \mathrm{GF}_{254} \quad 0.25 \mathrm{~mm}$ (Merck). Pereaksi Dragendroff digunakan sebagai penampak noda senyawa alkaloid. Bahan untuk kultur sel adalah medium RPMI-1640, fetal bovine serum (FBS), garam MTT, phosphate-buffered saline (PBS) dan dimetil sulfoksida (DMSO) sebagai bahan uji aktivitas anti-kanker. Instrumentasi yang digunakan dalam penentuan struktur alkaloid hasil isolasi antara lain meliputi spektrometer UV-Vis Shimadzu 1800, spektrometer IR Shimadzu, spektrometer NMR JEOL ECA 400 yang beroperasi pada $400 \mathrm{MHz}$.

\section{Bahan Tanaman}

Sampel penelitian adalah ranting Toddalia asiatica $L$. dari Sabungan Jae, Kecamatan Padangsidempuan Barat, Kabupaten Padangsidempuan, Sumatra Utara. Identifikasi tumbuhan dilakukan di Herbarium Bogoriensis, Bogor, Jawa Barat.

\section{Ekstraksi dan Isolasi}

Ekstraksi serbuk ranting Toddalia asiatica $L$. seberat $7,2 \mathrm{~kg}$ menggunakan metanol pada suhu kamar dengan cara maserasi selama 24 jam dan dilakukan sebanyak dua kali. Hasil maserasi disaring dan pelarut diuapkan menggunakan rotary vacuum evaporator untuk menghasilkan ekstrak kental metanol (900 gr). Hasil kromaografi lapis tipis (KLT) senyawa alkaloid positif memperlihatkan adanya spot coklat kemerahan dengan pereaksi Dragendoff. Ekstrak kental metanol dipartisi dengan $n$-heksana.

Ekstraksi metanol ditambahkan asam sulfat 5\% pH 3-4 dan dipartisi dengan etil asetat. Fasa asam ditambahkan ammoniak sampai larutan $\mathrm{pH} 9$ dan dipartisi dengan etil asetat menghasilkan ekstrak etil asetat (ekstrak alkaloid). Ekstrak kental etil asetat dicuci dengan air sampai $\mathrm{pH} \quad 7$ menghasilkan ekstrak alkaloid sebanyak 6,53 gr.

Pemisahan ekstrak alkaloid dengan kromatografi kolom gravitasi (KKG) menggunakan campuran $n$-heksana : etil asetat (9:1 sampai 3:7) menghasilkan lima fraksi utama A-E. Pemisahan fraksi C (781,8 $\mathrm{mg})$ dengan kromatografi radial dengan eluen $n$-heksana : kloroform (9:1 sampai 1:9), kloroform, dan kloroform : etil asetat 9:1 menghasilkan tiga subfraksi utama yaitu $\mathrm{C}_{1}-\mathrm{C}_{3}$. Pemurnian subfraksi $\mathrm{C}_{2}$ dilakukan dengan menggunakan kromatografi radial dengan eluen $n$-heksana : kloroform (8:2 sampai 3:7), kloroform, kloroform : etil asetat 9:1 menghasilkan senyawa alkaloid murni sebanyak $19,7 \mathrm{mg}$ yang berwujud padatan coklat kekuningan. 


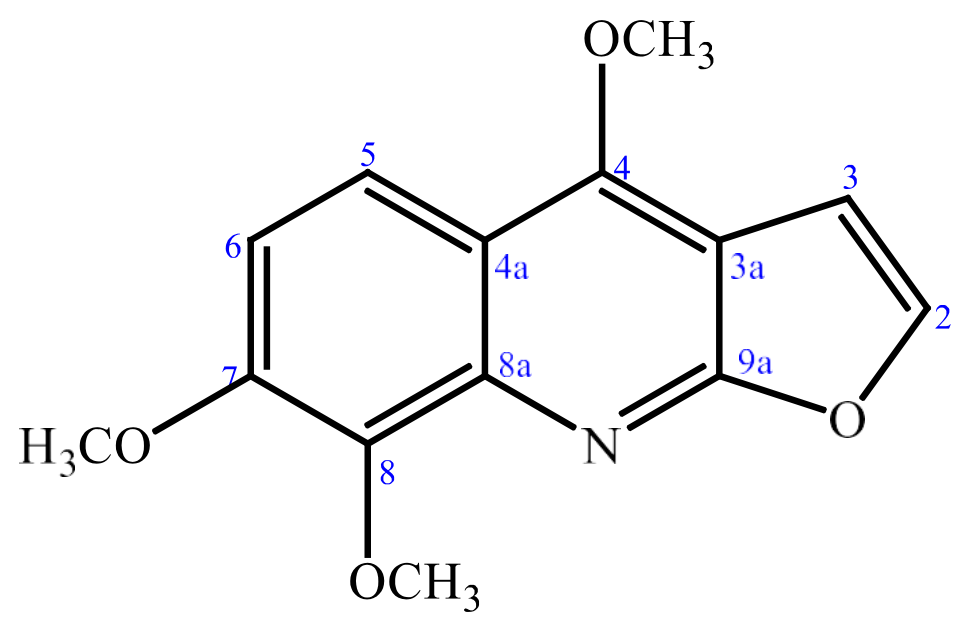

Gambar 1. Struktur senyawa skimmianin hasil isolasi

\section{Skimmianin}

Senyawa alkaloid berwujud padatan coklat kekuningan dengan titik leleh sebesar $176-178^{\circ} \mathrm{C}$. Spektrum UV $(\mathrm{MeOH})$ $\lambda_{\text {maks }} \mathrm{nm}(\log \varepsilon): 241 \mathrm{sh}(3,82) ; 249(3,99)$; 269 (2,96); $281(1,91) ; 291(2,93) ; 293$ $(2,93) ; 319 \quad(3,07)$; dan $331 \quad(3,05)$. Spektrum IR $(\mathrm{KBr}) \bar{v}_{\text {maks }}\left(\mathrm{cm}^{-1}\right): 3132$ (vibrasi ulur $\mathrm{C}=\mathrm{C}$ furo); 3920 (vibrasi ulur $\mathrm{C}-\mathrm{H}$ aromatik), 3853 (vibrasi ulur C-H aromatik), 1622; 1587; 1510; 1385; 1367

(vibrasi ulur $\mathrm{C}=\mathrm{C}$ aromatik), dan 1092 (vibrasi tekuk C-O eter). Spektrum ${ }^{1} \mathrm{H}-$ NMR dan C-NMR $\left(\mathrm{CDCl}_{3}\right)$ dapat dilihat pada Tabel-1.

\section{Uji aktivitas antikanker}

Uji aktivitas antikanker ekstrak etilasetat dan senyawa hasil isolasi terhadap sel kanker leukemia murin P-388 menggunakan analisis MTT setelah inkubasi selama 24 jam dalam inkubator $\mathrm{CO}_{2}$ pada suhu $37^{\circ} \mathrm{C}$.

\section{Hasil dan Pembahasan}

Skimmianin berwujud padatan coklat kekuningan dengan titik leleh $176-178^{\circ} \mathrm{C}$. Spektrum UV senyawa alkaloid dalam metanol memperlihatkan serapan panjang gelombang maksimum pada $\lambda_{\text {maks }} \mathrm{nm}$ (log
ع) : $241 \mathrm{sh}(3,82) ; 249(3,99) ; 269$ (2,96);

$281(1,91) ; 291(2,93) ; 293(2,93) ; 319$ $(3,07)$; dan $331(3,05)$.

Spektrum IR senyawa memperlihatkan $\bar{v}_{\text {maks }}\left(\mathrm{cm}^{-1}\right): 3132$ (vibrasi ulur $\mathrm{C}=\mathrm{C}$ furo); 2920 (vibrasi ulur C-H aromatik), 2853 (vibrasi ulur C-H aromatik), 1622; 1587; 1510; 1385; 1367 (vibrasi ulur $\mathrm{C}=\mathrm{C}$ aromatik), dan 1092 (vibrasi tekuk C-O eter terkonjugasi).

Spektrum ${ }^{1} \mathrm{H}-\mathrm{NMR}(400 \mathrm{MHz})$ senyawa alkaloid kuinolin turunan furokuinolin dalam $\mathrm{CDCl}_{3}$ memperlihatkan tujuh sinyal proton pada daerah pergeseran kimia $\delta_{\mathrm{H}}$ $4,02-8,01 \mathrm{ppm}$. Dua sinyal proton diantara tujuh sinyal proton tersebut merupakan sinyal proton aromatik. Sinyal proton aromatik tersebut merupakan sinyal proton aromatik yakni sepasang sinyal proton orto aromatik $(J=9,3 \mathrm{~Hz})$ pada $\delta_{\mathrm{H}} 8,01$ dan $\delta_{\mathrm{H}}$ $7,22 \mathrm{ppm}$. Sepasang sinyal proton doblet $(J$ $=2,8 \mathrm{~Hz}$ ) pada $\delta_{\mathrm{H}} 7,57$ dan $\delta_{\mathrm{H}} 7,03 \mathrm{ppm}$ merupakan sinyal proton dari cincin furo (Parhoodeh et al., 2012). Analisis spektrum ${ }^{1} \mathrm{H}-\mathrm{NMR}$ memperlihatkan adanya tiga sinyal proton dari metoksi pada $\delta_{\mathrm{H}} 4.42$, 4,02 dan 4,10 ppm. Spektrum ${ }^{13} \mathrm{C}-\mathrm{NMR}$ (percobaan APT) senyawa skimmianin memperlihatkan 14 sinyal karbon yang terpisah secara sempurna. Sinyal karbon 
senyawa alkaloid hasil isolasi terdistribusi atas empat atom karbon tersier $\mathrm{CH}\left(\delta_{\mathrm{C}}\right.$ 143,$1 ; 118,3 ; 112,0 ; 104,7$ ppm); tujuh atom karbon kuartener $\left(\delta_{\mathrm{C}} 164,4 ; 157,3\right.$; 152,$2 ; 141,9 ; 141,5 ; 114,9 ; 103.4$ ppm) dan tiga atom karbon primer dari metoksi $\left(\delta_{\mathrm{C}}\right.$ 61,7; 56,8; dan 59.1 ppm). Berdasarkan data spektrum 1D dan 2D NMR maka struktur senyawa alkaloid furokuinolin hasil isolasi adalah 4,7,8-trimetoksi furo$[2,3, b]$ kuinolin atau dikenal dengan nama senyawa skimmianin (Parhoodeh et al., 2012). Berdasarkan spektrum NMR senyawa skimmianin hasil isolasi memperlihatkan kesesuaian yang tinggi dengan data spektrum NMR senyawa skimmianin yang diisolasi dari daun tumbuhan Haplophyllum laeviusculum (Parhoodeh et al., 2012). Spektrum HMBC menunjukkan korelasi antara sinyal proton dengan sinyal karbon dalam dua atau tiga ikatan yang utama untuk mendukung struktur senyawa skimmianin.

Penempatan tiga gugus metoksi pada struktur alkaloid furokuinolin hasil isolasi berdasarkan spektrum HMBC terdapat dua proton dari cincin furo yang mempunyai posisi di H-2 dan H-3. Sinyal proton pada $\delta_{\mathrm{H}}$ 7,57 memperlihatkan korelasi dua sinyal karbon kuarterner $\left(\delta_{\mathrm{C}} 103.4\right)$ dan satu sinyal karbon metin $\left(\delta_{\mathrm{C}} 104,7 \mathrm{ppm}\right)$. Sinyal proton dari cincin furo yang lain pada $\delta_{\mathrm{H}} 7,03 \mathrm{ppm}$ memperlihatkan korelasi dua sinyal karbon kuarterner $\left(\delta_{\mathrm{C}} 103.4\right.$ dan $\left.\delta_{\mathrm{C}} 164,4 \mathrm{ppm}\right)$ dan satu sinyal karbon metin $\left(\delta_{\mathrm{C}} 143,1 \mathrm{ppm}\right)$.

Sinyal proton aromatik pada $\delta_{\mathrm{H}} 8,01$ ppm memperlihatkan korelasi dengan tiga sinyal karbon kuarterner $\left(\delta_{\mathrm{C}} 157,3 ; \quad \delta_{\mathrm{C}}\right.$ 152,$\left.2 ; \delta_{\mathrm{C}} 141,5 \mathrm{ppm}\right)$. Sinyal karbon kuarterner pada $\delta_{\mathrm{C}} 157,3$ dan $\delta_{\mathrm{C}} 152,2$ merupakan gugus metoksi. Sinyal singlet dari metoksi pada $\delta_{\mathrm{H}} 4,42$ memperlihatkan korelasi dengan sinyal karbon oksiaril pada $\delta_{\mathrm{C}} 157,3$. Sinyal singlet metoksi yang lain pada $\delta_{\mathrm{H}} 4,10$ berkorelasi dengan sinyal karbon oksiaril pada $\delta_{\mathrm{C}} 152,2$. Sinyal proton aromatik yang lain pada $\delta_{\mathrm{H}} 7,22$ memperlihatkan korelasi tiga sinyal karbon kuarterner $\left(\delta_{\mathrm{C}} 152,2 ; \delta_{\mathrm{C}} 141,9 ; \delta_{\mathrm{C}} 114,9\right.$ ppm). Sinyal singlet dari metoksi pada $\delta_{H}$ 4,10 memperlihatkan korelasi dengan sinyal karbon oksiaril pada $\delta_{\mathrm{C}} 152,2$. Sinyal singlet metoksi yang lain pada $\delta_{\mathrm{H}} 4,02$ berkorelasi dengan sinyal karbon oksiaril pada $\delta_{\mathrm{C}} \delta_{\mathrm{C}}$ 141,9. Adanya korelasi proton aromatik pada $\delta_{\mathrm{H}} 7,22$ dengan dua sinyal karbon oksiaril $\left(\delta_{\mathrm{C}} 152,2\right.$ dan $\left.\delta_{\mathrm{C}} 141,9\right)$ merupakan ciri khas oksiaril posisi orto. Hasil korelasi dari dua sinyal proton aromatik dan tiga sinyal proton metoksi mempertegas kedudukan sinyal karbon $\delta_{\mathrm{C}} 157,3$ di C-4, $\delta_{\mathrm{C}} 152,2$ di C-7 dan $\delta_{\mathrm{C}} 141,9$ di C-8. Hasil korelasi ini menunjukkan sinyal proton aromatik pada $\delta_{\mathrm{H}} 8,01$ berkedudukan di $\mathrm{H}-5$ dan $\delta_{\mathrm{H}}$ 7,22 di H-6. Korelasi antara sinyal proton dengan sinyal karbon dalam dua atau tiga ikatan pada spektrum HMBC yang mendukung struktur senyawa skimmianin hasil isolasi dapat dilihat pada Tabel-1 dan Gambar-2. 
Tabel-1. Data spektrum ${ }^{1} \mathrm{H}$ dan ${ }^{13} \mathrm{C}-\mathrm{NMR}$ senyawa skimmianin dalam $\mathrm{CDCl}_{3}$.

\begin{tabular}{cccc}
\hline No.C & $\boldsymbol{\delta}_{\mathbf{H}}(\mathbf{m u l t}, \boldsymbol{J}$ dalam $\mathbf{H z})$ & $\boldsymbol{\delta} \mathbf{C}$ & $\mathbf{H M B C}$ \\
\hline 2 & $7,57(d, 2.8)$ & 143,1 & $\mathrm{C}-3 ; \mathrm{C}-3 \mathrm{a}, \mathrm{C}-9 \mathrm{a}$ \\
3 & $7,03(d, 2.8)$ & 104,7 & $\mathrm{C}-2 ; \mathrm{C} 3 \mathrm{a} ; \mathrm{C}-9 \mathrm{a}$ \\
$3 \mathrm{a}$ & - & 103.4 & - \\
4 & - & 157,3 & - \\
$4 \mathrm{a}$ & - & 114,9 & - \\
5 & $8,01(d, 9,3)$ & 118,3 & $\mathrm{C}-4 ; \mathrm{C}-7 ; \mathrm{C}-8 \mathrm{a}$ \\
6 & $7,22(d, 9,3)$ & 112,0 & $\mathrm{C}-4 \mathrm{a} ; \mathrm{C}-7 ; \mathrm{C}-8$ \\
7 & - & 152,2 & - \\
8 & - & 141,9 & - \\
$8 \mathrm{a}$ & - & 141,5 & - \\
$9 \mathrm{a}$ & - & 164,4 & - \\
$4-\mathrm{OCH}_{3}$ & $4.42(s)$ & 59.1 & $\mathrm{C}-4$ \\
$7-\mathrm{OCH}_{3}$ & $4,02(s)$ & 56,8 & $\mathrm{C}-7$ \\
$8-\mathrm{OCH}_{3}$ & $4,10(s)$ & 61,7 & $\mathrm{C}-8$ \\
\hline
\end{tabular}

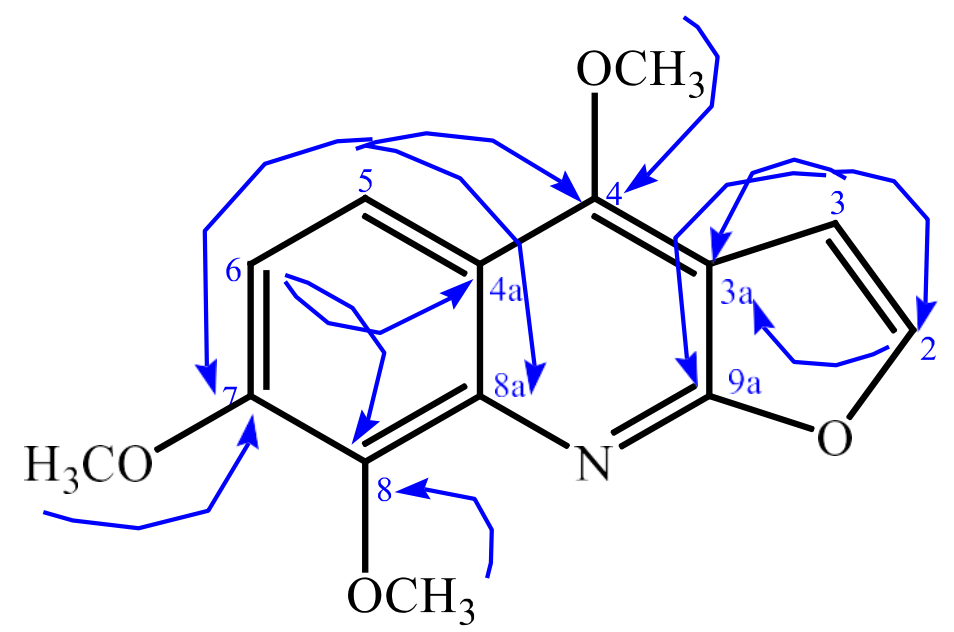

Gambar 2. Korelasi HMBC yang utama senyawa skimmianin hasil isolasi

Uji aktivitas antikanker ekstrak alkaloid dan senyawa skimmianin terhadap sel kanker leukemia murin P-388 memperlihatkan nilai $\mathrm{IC}_{50}$ sebesar $4,96 \mathrm{ppm}$ dan dikategorikan lemah.

\section{Kesimpulan}

Senyawa alkaloid turunan furokuinolin, skimmianin telah berhasil diisolasi dari ranting Toddalia asiatica L. Struktur senyawa hasil isolasi ditetapkan berdasarkan analisis spektroskopi, meliputi UV, IR, 1D dan 2D NMR. Uji aktivitas antikanker senyawa skimmianin dan ekstrak etilasetat terhadap sel kanker leukemia murin P-388 memperlihatkan nilai $\mathrm{IC}_{50}$ sebesar $4,96 \mathrm{ppm}$ yang dikategorikan lemah.

\section{Daftar Pustaka}

Hirunwong, C., Sukieuma, S., Phatchanab, R., Yenjaia, C., 2016, Cytotoxic and antimalarial constituents from the roots of Toddalia asiatica, Phyto. Chem. Lett., 17, 242-246. 
Hu, Jiang., Shi, Xiaodong., Mao, Xia., Chen, Jiangang., Li, Hui, 2015, Amides from the roots of Toddalia asiatica, Chem. Nat. Comp., 51(4).

Li, W., Zhang J.S., Huang, J.L., Jiang, M.H., Xu, Y.K., Ahmed, A., Yina, S., and Tang, G.H., 2017, New prenylated coumarins from the stems of Toddalia asiatica. Royal. Chem. Soc., vol. 7.

Parhoodeh, P., Rahmani, M., Hashim, N.M., Sukari, M.A., Lian Ee, G.C.,
2012, Alkaloid Constituents of Haplophyllum laeviusculum (Rutaceae), Sains. Malay., 41(1), 4752.

Qui, H., Xiao, X., Li, G., 2012, Separation and purification of furanocoumarins from Toddalia asiatica (L.) Lam. using microwave-assisted extraction coupled with high-speed counter-current chromatography, J. Sep. Sci. 